\title{
Effects of a Nebulized NONOate, DPTA/NO, on Group B Streptococcus-Induced Pulmonary Hypertension in Newborn Piglets
}

\author{
KATARZYNA DABROWSKA, DOROTHY HEHRE, KAREN C. YOUNG, CRISTINA NAVARETTE, \\ JOHN F. LADINO, EDUARDO BANCALARI, AND CLEIDE SUGUIHARA \\ Department of Pediatrics, Division of Neonatology, University of Miami School of Medicine Miami, FL \\ 33101
}

\begin{tabular}{|c|c|}
\hline \multicolumn{2}{|c|}{ ABSTRACT } \\
\hline $\begin{array}{l}\text { NONOates are chemical compounds that are stable as solids } \\
\text { but generate nitric oxide (NO) in aqueous solutions. When } \\
\text { nebulized or instilled intratracheally, NONOates can attenuate } \\
\text { pulmonary hypertension in adult animals with lung injury. To } \\
\text { assess the effect of a nebulized NONOate, DPTA/NO, on group } \\
\text { B Streptococcus (GBS)-induced pulmonary hypertension in new- } \\
\text { born piglets, we studied } 20 \text { anesthetized and mechanically ven- } \\
\text { tilated piglets ( } 4-10 \text { d). They were randomly assigned to receive } \\
\text { nebulized placebo solution or DPTA/NO ( } 100 \text { mg) } 15 \text { min after } \\
\text { sustained pulmonary hypertension. Pulmonary artery and wedge, } \\
\text { systemic, and right atrial pressures; cardiac output; and arterial } \\
\text { blood gases were obtained at baseline and every } 15 \text { min during } \\
120 \text { min of continuous GBS infusion ( } 6 \text { } 10^{8} \text { CFU/min). } \\
\text { Methemoglobin levels were measured at baseline and } 60 \text { min. A } \\
\text { significant decrease in pulmonary artery pressure, pulmonary } \\
\text { vascular resistance (PVR), systemic arterial pressure, and sys- } \\
\text { temic vascular resistance (SVR) was observed after DPTA/NO } \\
\text { nebulization ( } p<0.001) \text {. Whereas the increase in PVR/SVR } \\
\text { observed after GBS infusion was sustained for } 120 \text { min in the } \\
\text { placebo group, this ratio decreased after DPTA/NO nebulization } \\
\text { and remained significantly lower throughout the study period } \\
\text { ( } p<0.01 \text { ). Cardiac output, arterial blood gases, and methemo- } \\
\text { globin values did not differ between groups. These data demon- } \\
\text { strate that the pulmonary hypertension induced by GBS infusion } \\
\text { is markedly attenuated by DPTA/NO nebulization. The lower }\end{array}$ & $\begin{array}{l}\text { PVR/SVR observed in the treated group indicates that the vaso- } \\
\text { dilatory effect of NONOate is more pronounced in the pulmonary } \\
\text { than systemic vasculature. Therefore, NONOates may have clin- } \\
\text { ical application in the management of pulmonary hypertension } \\
\text { secondary to sepsis in neonates. (Pediatr Res 57: 378-383, 2005) } \\
\qquad \text { Abbreviations } \\
\text { ABG, arterial blood gas } \\
\text { BL, baseline } \\
\text { CO, cardiac output } \\
\text { Crs, respiratory compliance } \\
\text { GBS, group B Streptococcus } \\
\text { iNO, inhaled nitric oxide } \\
\text { NO, nitric oxide } \\
\text { Paw, mean airway pressure } \\
\text { PL, placebo } \\
\text { Ppa, pulmonary artery pressure } \\
\text { Pra, right atrial pressure } \\
\text { Psa, systemic arterial pressure } \\
\text { PVR, pulmonary vascular resistance } \\
\text { Pwp, pulmonary wedge pressure } \\
\text { R , respiratory resistance } \\
\text { SVR, systemic vascular resistance } \\
\mathbf{V}_{\mathbf{T}} \text {, tidal volume }\end{array}$ \\
\hline
\end{tabular}

Group B Streptococcus (GBS) sepsis is characterized by pulmonary hypertension, arterial hypoxemia, metabolic acidosis, decreased cardiac output (CO), and systemic hypotension progressing sometimes to irreversible shock (1). Despite modern

Received April 15, 2003; Accepted July 12, 2004.

Correspondence: Cleide Suguihara, University of Miami School of Medicine, Department of Pediatrics (R-131), P.O. Box 016960, Miami, FL 33101; e-mail: csuguihara@miami.edu

Supported by the University of Miami: Project New Born, Bachelor Children's Research Institute Department of Pediatrics, Division of Neonatology, University of Miami School of Medicine.

Presented in part at the Society for Pediatric Research, May 2002, Baltimore, MD.

DOI: 10.1203/01.PDR.0000150802.35283.27 intensive care, this condition continues to carry high morbidity and mortality. Many modalities have been proposed for the management of pulmonary hypertension, including cytokine inhibitors and vasodilators (2-7). However, clinical application of these modalities is limited because of significant side effects and lack of selectivity to the pulmonary vasculature.

Inhaled nitric oxide (iNO) has emerged in recent years as an effective and selective treatment modality for pulmonary hypertension. Its effectiveness in treating persistent pulmonary hypertension of the newborn was documented in a number of animal models and also clinical trials $(8,9)$. In animal models of pulmonary hypertension induced by GBS sepsis, iNO was 
effective in reducing pulmonary hypertension in both early and late phase (10-12). However, the short half-life of iNO is a major shortcoming, which requires its continuous delivery (13).

A possible alternative to iNO is a group of compounds called NONOates, or diazeniumdiolates (14). These products are usually stable as solids but nonenzymatically decompose in solution at a rate that depends on $\mathrm{pH}$, temperature, and the identity of the carrier nucleophile (14-17). On decomposing, they release 1-2 mol of $\mathrm{NO}$ and the nucleophile carrier. Individual diazeniumdiolates tend to have reproducible rates of dissociation. DPTA/NO, which was used in this study, is one of the polyamine NONOates, with a half-life ranging from 1 to $5 \mathrm{~h}$, depending on the temperature and $\mathrm{pH}(14-17)$. Intermittent nebulization or intratracheal instillation of a NONOate can slowly release NO into the pulmonary vasculature without producing significant systemic side effects. Therefore, NONOates are an interesting alternative to continuous iNO administration, which could potentially reduce caregivers' exposure to toxic by-products and allow an intermittent dosing schedule. It was demonstrated previously that NONOates attenuate the pulmonary hypertension induced by thromboxane agonists, endothelium-derived NO inhibitor, oleic acid infusion, and monocrotaline injection in pigs, lambs, and rats (18-25).

To the best of our knowledge, there is no published data testing the effectiveness and selectivity of NONOates in attenuating pulmonary hypertension as a result of GBS infusion in newborn animals. Therefore, we hypothesized that GBSinduced pulmonary hypertension can be attenuated by the administration of the NONOate, DPTA/NO. Furthermore, the vasodilatory effect of DPTA/NO is selective to the pulmonary vasculature. The objective of the present study was to evaluate the cardiorespiratory effects of the nebulized NONOate, DPTA/NO in newborn piglets with GBS-induced pulmonary hypertension.

\section{METHODS}

Animal model. Twenty Yorkshire neonatal piglets with a mean weight of $2.3 \pm 0.5 \mathrm{~kg}$, age $6 \pm 1.0 \mathrm{~d}$, were anesthetized with Ketamine $20 \mathrm{mg} / \mathrm{kg}$ and Xylazine $2 \mathrm{mg} / \mathrm{kg}$, i.m. Anesthesia was maintained throughout the study with propofol $(3 \mathrm{mg} / \mathrm{kg}$ i.v. as a bolus, followed by a continuous infusion of 10 $\left.\mathrm{mg} \cdot \mathrm{kg}^{-1} \cdot \mathrm{h}^{-1}\right)$.

A tracheostomy was performed, and a 4.0- to $4.5-\mathrm{mm}$ endotracheal tube was inserted and secured in position with a silk suture. Left and right femoral arteries and veins were cannulated and used for systemic arterial blood pressure measurements, blood sampling, fluids administration, and GBS infusion. A 5F Swan-Ganz thermodilution catheter was introduced into the right external jugular vein, advanced under fluoroscopy into the left pulmonary artery, and used to measure $\mathrm{CO}$ and pulmonary artery (Ppa) and wedge pressures (Pwp). The left external jugular vein was cannulated and used for right atrial pressure (Pra) measurements. Ppa, Psa, Pra, and Pwp were measured with pressure transducers (Model P23; Gould Instruments, Cleveland, $\mathrm{OH}$ ) and recorded on a multichannel recorder (Model 2800; Gould Instruments). $\mathrm{CO}$ was measured by thermodilution using a $\mathrm{CO}$ computer (Model 9510-A; Edwards Laboratories, Santa Ana, CA). A maximum of four samples were obtained, and the average value from two measurements with $<10 \%$ difference was calculated (26). Pulmonary vascular resistance (PVR) was calculated using the formula [(Ppa - Pwp $) / \mathrm{CO} / \mathrm{kg})]$, and systemic vascular resistance (SVR) was calculated using the formula [(Psa - Pra) $/(\mathrm{CO} / \mathrm{kg})]$.

During the study period, the animals were ventilated with a time-cycled, pressure-limited infant ventilator (Model IV-100B; Sechrist Industries, Anaheim, CA). Respiratory flow was measured with a Fleisch no. 0 pneumotachometer (OEM Medical, Richmond, VA) placed between the endotracheal tube and the ventilator circuit (Isothermal Airlife Breathing Circuit; Allegiance Healthcare Corp., McGaw Park, IL). The differential pressure output from the pneumotachometer was measured with a transducer (Model MP 45; Validyne Engineering Co., Northridge, CA) and amplified by a pressure amplifier (Gould Instruments). The flow signal was electronically integrated to obtain tidal volume $\left(\mathrm{V}_{\mathrm{T}}\right)$ using a Gould integrator amplifier. Calibration of $\mathrm{V}_{\mathrm{T}}$ was done before and after each study using a calibrated glass syringe. Airway pressure (Paw) was measured by connecting the pressure line of the ventilator to a pressure transducer (model P23-ID; Gould Instruments) and amplifying the signal with a Gould pressure amplifier.

Air flow, $\mathrm{V}_{\mathrm{T}}$, and Paw were recorded on multichannel recorder (Model 2400; Gould Instruments), and respiratory compliance (Crs) and total respiratory resistance $\left(\mathrm{R}_{\mathrm{T}}\right)$ were calculated as previously described (4). Ventilator settings were adjusted during the study to maintain $\mathrm{V}_{\mathrm{T}}$ of $10 \mathrm{~mL} / \mathrm{kg}$ and arterial partial pressure of $\mathrm{CO}_{2}$ between 30 and $45 \mathrm{~mm} \mathrm{Hg}$. Animals were ventilated with $100 \%$ oxygen.

Arterial blood gases (ABG) were measured by using a blood gas analyzer (Model 238; Ciba-Corning, Essex, England) and corrected for core temperature. Methemoglobin concentration was determined using a co-oximeter (IL 482 CO-Oximeter System; Instrumentation Laboratory Company, Lexington, MA).

The rectal temperature was monitored continuously with a thermistor probe (model 6510; Mallinckrodt Medical, St. Louis, MO) and maintained at $38^{\circ} \mathrm{C}$ by means of a servo-controlled radiant warmer. The animals received an infusion of $6 \mathrm{~mL} \cdot \mathrm{kg}^{-1} \cdot \mathrm{h}^{-1}$ of $5 \%$ Ringer Lactate solution through a femoral vein and a heparinized normal saline solution $(10 \mathrm{U} / \mathrm{mL})$ through the pulmonary artery catheter.

Bacterial preparation. GBS type I a/c isolated from an infected neonate were cultured in Todd-Hewitt broth for $18 \mathrm{~h}$ at $37^{\circ} \mathrm{C}$. The organisms were collected by centrifugation, washed, and re-suspended in sterile Ringer's Lactate solution with $5 \%$ dextrose at a concentration determined by OD measurements to be equivalent to $9.6 \times 10^{10} \mathrm{CFU} / \mathrm{mL}$. The bacterial cell suspension was free of endotoxin as determined by a Limulus Amebocyte Lysate test (Associate of Cape Cod, MA) which had sensitivity of $>0.03$ $\mathrm{EU} / \mathrm{mL}$.

Drug Preparation. Immediately before administration, DPTA/NO $100 \mathrm{mg}$ was dissolved in $2 \mathrm{~mL}$ of $0.9 \% \mathrm{NaCl}$ and delivered via nebulization over 15 min, using an in-line nebulizer (Airlife Misty-Neb Nebulizer, Allegiance Healthcare Corp.) driven by $100 \%$ oxygen at a flow rate of $4 \mathrm{~L} / \mathrm{min}$, placed immediately next to the endotracheal tube on the inspiratory limb of the ventilator circuit. This dose was selected after dose-response studies with DPTA/NO (Cayman Chemical Co., Ann Arbor, MI) were performed during continuous infusion of GBS. We tested doses of 25, 50, 100, and $200 \mathrm{mg}$. Administration of low doses (25 and $50 \mathrm{mg}$ ) resulted in a $10 \%$ reduction in Ppa after 15 min of nebulization and no effects on systemic arterial pressure (Psa). Administration of $200 \mathrm{mg}$ resulted in a reduction in Ppa by 50\% within $15 \mathrm{~min}$ of nebulization; however, there was also a maximum reduction in Psa by $38 \%$. The dose of $100 \mathrm{mg}$ was chosen on the basis of attenuation of pulmonary hypertension by at least 30\% (from 15-min measurements) with minimal systemic effects.

Pulmonary hypertension protocol. After a period of stabilization, baseline hemodynamic measurements (Ppa, Psa, Pra, Pwp, and CO), pulmonary mechanics $\left(\mathrm{Crs}, \mathrm{R}_{\mathrm{T}}, \mathrm{V}_{\mathrm{T}}\right.$, and Paw), and $\mathrm{ABG}$ were obtained. Immediately after measurements were completed, a continuous infusion of GBS at $6 \times 10^{8}$ $\mathrm{CFU} / \mathrm{min}$ was started and all measurements were repeated after $15 \mathrm{~min}$ of sustained pulmonary hypertension, which was defined as an elevation of Ppa of at least $50 \%$ above baseline.

The animals were randomly assigned to receive nebulized DPTA/NO (100 $\mathrm{mg}$ ) dissolved in $2 \mathrm{~mL}$ of saline or placebo (PL; $2 \mathrm{~mL}$ of normal saline). All hemodynamic measurements and ABG were recorded every 15 min until $2 \mathrm{~h}$. $\mathrm{V}_{\mathrm{T}}$ was monitored continuously, and pulmonary mechanics were measured every $30 \mathrm{~min}$. Arterial blood samples for methemoglobin measurements were obtained at baseline and $60 \mathrm{~min}$

At the conclusion of the study, all animals were killed with Eutasol solution $(0.5 \mathrm{~mL} / \mathrm{kg})$. Handling and care of the animals were in accordance with the guidelines of the National Institutes of Health, and the study protocol was approved by the Animal Care Committee of the University of Miami.

Statistical analysis. Repeated measures ANOVA was used to compare the pattern of response between the DPTA/NO and PL group over time (time $\times$ treatment interaction) and independent of time (overall group difference) for the dependent variables. Dependent variables include Ppa, Psa, PVR, SVR, $\mathrm{PVR} / \mathrm{SVR}, \mathrm{ABG}$, acid-base status, $\mathrm{Crs}$, and $\mathrm{R}_{\mathrm{T}}$. One factor repeated measures ANOVA was also used to evaluate the effects of GBS infusion on Crs and $\mathrm{R}_{\mathrm{T}}$ within group (PL or DPTA/NO). Data are expressed as mean $\pm \mathrm{SD}$, and $p<$ 0.05 was considered significant. 


\section{RESULTS}

Ten newborn piglets (weight: $2.3 \pm 0.5 \mathrm{~kg}$; age: $6 \pm 1 \mathrm{~d}$ ) were nebulized with DPTA/NO, and 10 animals (weight: $2.5 \pm$ $0.3 \mathrm{~kg}$; age: $6 \pm 2 \mathrm{~d}$ ) received nebulization with normal saline. Weight and age were not different between groups. The hemodynamic measurements, and ABG and pulmonary mechanics values also were not significantly different between groups before GBS infusion.

Fifteen minutes after the beginning of GBS infusion, Ppa increased 2.5-fold in both groups (DPTA/NO: $11 \pm 2$ to $28 \pm$ $5 \mathrm{~mm} \mathrm{Hg}$; PL: $11 \pm 3$ to $29 \pm 4 \mathrm{~mm} \mathrm{Hg}$ ). However, after DPTA/NO nebulization, a significant decrease in Ppa was observed during 120 min of GBS infusion, whereas in the PL group, it remained elevated throughout the study period (Fig. 1A). Similarly, PVR increased significantly in both groups after $15 \mathrm{~min}$ of GBS infusion (DPTA/NO: $27 \pm 12$ to $115 \pm 57 \mathrm{~mm}$ $\mathrm{Hg} \cdot \mathrm{L}^{-1} \cdot \mathrm{min}^{-1} \cdot \mathrm{kg}^{-1}$; PL: $30 \pm 14$ to $117 \pm 42 \mathrm{~mm} \mathrm{Hg} \cdot$ $\mathrm{L}^{-1} \cdot \min ^{-1} \cdot \mathrm{kg}^{-1}$ ). However, PVR decreased significantly during GBS infusion, after DPTA/NO nebulization, whereas in

A

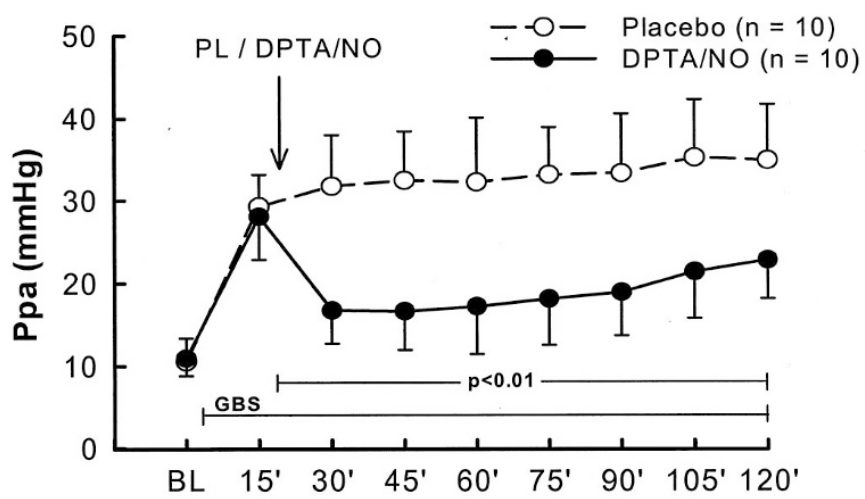

B

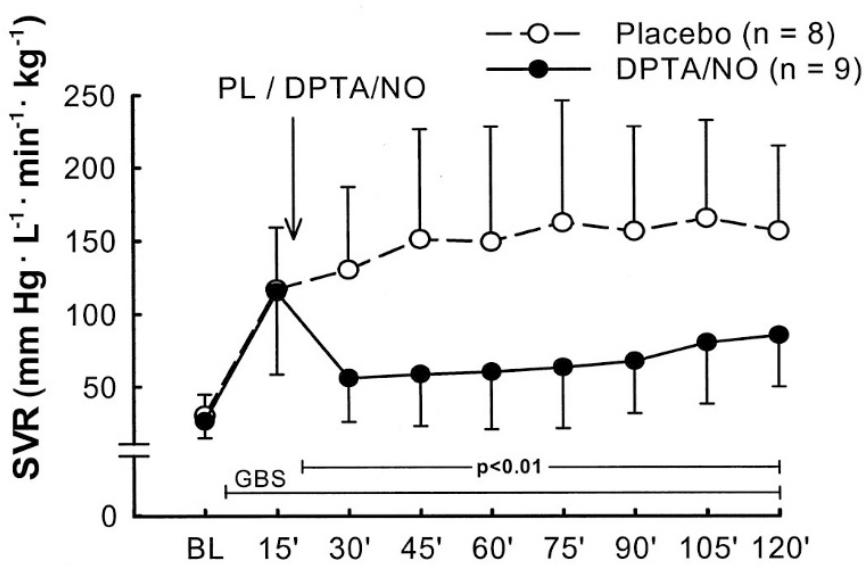

Figure 1. (A) Ppa changes in PL and DPTA/NO groups during GBS infusion. A marked increase in Ppa was observed in both groups after $15 \mathrm{~min}$ of GBS infusion. After DPTA/NO nebulization, Ppa decreased significantly, whereas it remained elevated in the PL group $(p<0.01)$. $(B)$ PVR changes during GBS infusion in PL and DPTA/NO groups. PVR increased significantly in both groups after 15 min of GBS infusion. However, a significant decrease in PVR was observed after DPTA/NO nebulization $(p<0.01)$. the PL group, it remained elevated throughout the study period (Fig. 1B).

A similar increase in Psa and SVR was observed in both groups after 15 min of GBS infusion. After DPTA/NO nebulization, Psa and SVR decreased significantly to values close to the baseline levels. In contrast, Psa and SVR remained elevated throughout the study period in the PL group (Fig. 2). In addition, a marked decrease in $\mathrm{CO}$ was observed in both groups after 15 min of GBS infusion. Changes in CO throughout the study period were not significantly different between the study groups (Fig. 3).

To evaluate the relative effect of DPTA/NO on the pulmonary and systemic vasculature, we calculated the ratio between PVR and SVR. A similar increase in PVR/SVR was observed after $15 \mathrm{~min}$ of GBS infusion in both groups. This ratio remained elevated throughout the study period in the PL group, whereas it decreased significantly after DPTA/NO nebulization. (Fig. 4)

Arterial partial pressure of oxygen, $\mathrm{pH}$, and base excess (BE) decreased progressively from the initiation of the GBS infusion until the end of the experiment in both study groups

A

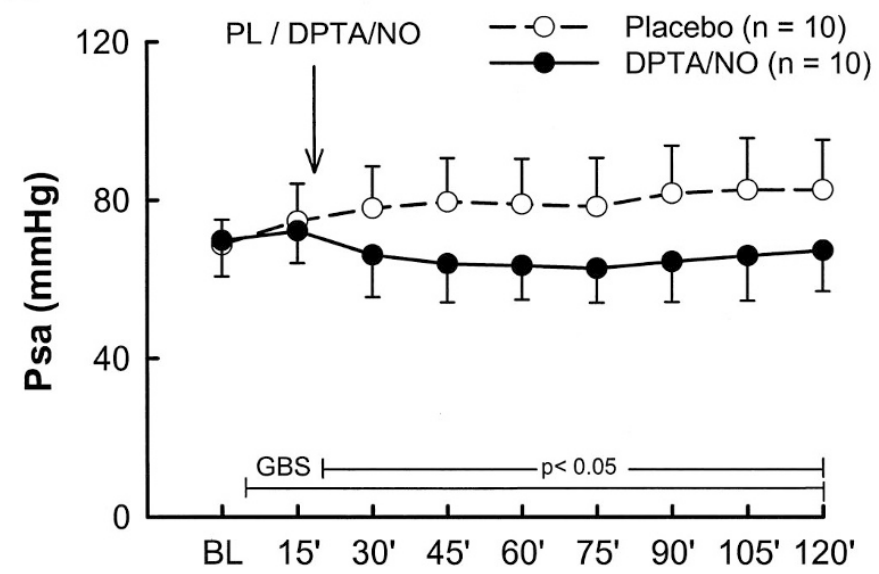

B

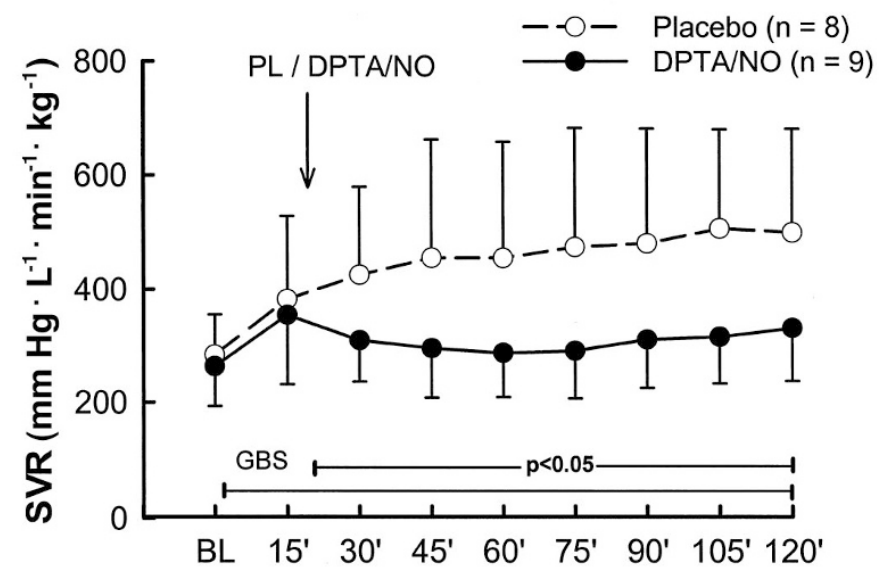

Figure 2. (A) Psa changes during GBS infusion in PL and DPTA/NO groups. After DPTA/NO nebulization, Psa decreased to values close to baseline level $(p<0.05)$. (B) SVR changes during GBS infusion in PL and DPTA/NO groups. SVR decreased significantly after DPTA/NO nebulization, but it remained close to the baseline values $(p<0.05)$. 


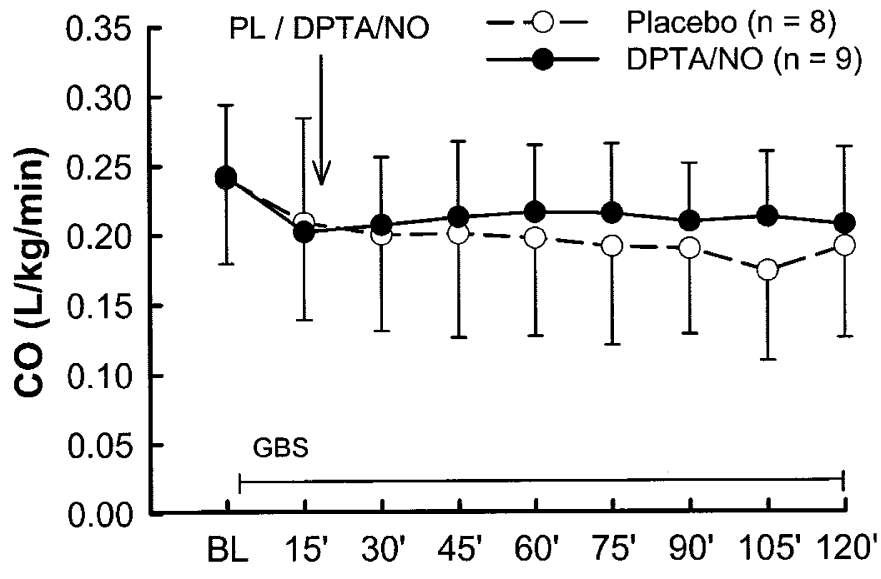

Figure 3. Changes in CO during GBS infusion in PL and DPTA/NO groups. The decrease in CO with GBS infusion was not statistically different between groups.

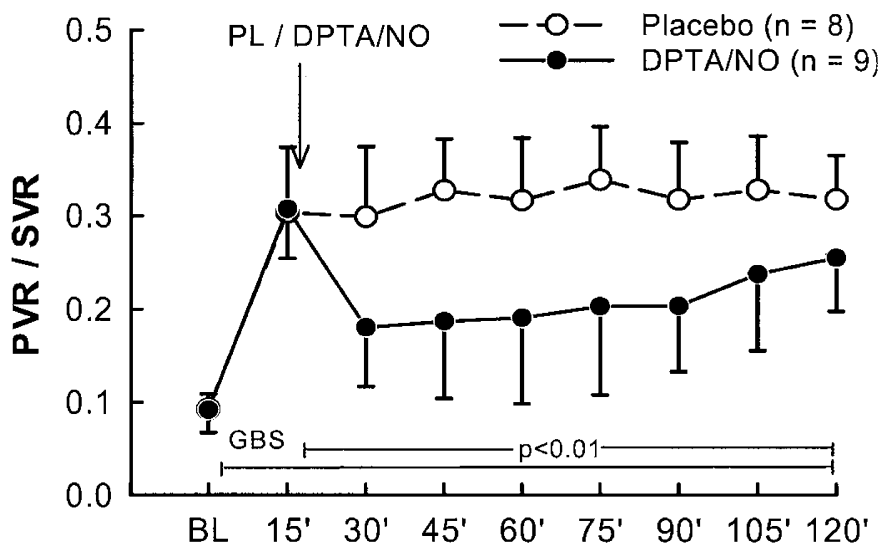

Figure 4. PVR/SVR changes during GBS infusion in PL and DPTA/NO groups. A significant increase in PVR/SVR was observed in both groups after 15 min of GBS infusion. This ratio remained elevated in PL group, but a marked decrease was observed after DPTA/NO nebulization $(p<0.01)$.

(Table 1). Ventilator rate and $\mathrm{V}_{\mathrm{T}}$ were not different between groups. A significant reduction in Crs and increase in $R_{T}$ was observed in PL and DPTA/NO groups over time during GBS infusion $(p<0.01)$. There was, however, no significant difference in Crs or $\mathrm{R}_{\mathrm{T}}$ between the groups throughout the study period (Table 2). The methemoglobin level was zero in both groups before and after nebulization.

\section{DISCUSSION}

The present study demonstrated that the NONOate DPTA/NO delivered via nebulization attenuates GBS-induced pulmonary hypertension in newborn piglets. Furthermore, the PVR/SVR was significantly lower in the NONOate group, indicating that its vasodilatory effect is more pronounced in the pulmonary than in the systemic vasculature.

NO has a very short half-life (3-4 s) and is rapidly inactivated in the circulation by binding to $\mathrm{Hb}$. Administration of iNO results in vasodilation of the pulmonary vasculature preferentially in the well-ventilated regions, thereby improving ventilation-perfusion matching. By decreasing pulmonary artery pressure below systemic levels, iNO can also decrease extrapulmonary shunting at the foramen ovale or ductal level. However, the clinical use of iNO is limited by its need for continuous delivery and by the high cost of the delivery and monitoring system. In addition, sudden discontinuation of iNO therapy can be associated with life-threatening deterioration of oxygenation and rebound pulmonary hypertension (13).

A novel group of NO donors, NONOates, is currently being investigated as a possible alternative way of delivering exogenous NO. NONOates can be administered i.v., intratracheally, via nebulization, or transdermally, and their half-life ranges between $2 \mathrm{~s}$ and several days $(14,15,17)$. The administration of different NONOates has been shown to attenuate pulmonary hypertension in several animal models. However, the possibility of associated systemic effects is controversial.

Adrie et al. (24) evaluated the effect of an ultrashort half-life ( 2 s) NONOate, PROLI/NO, on the pulmonary as well as the systemic vasculature in sheep with pulmonary hypertension induced by a thromboxane analog. The vasodilatory effect of PROLI/NO on the pulmonary circulation was dose dependent, and the systemic vasodilation was present only at the highest dose $\left(12 \mu \mathrm{g} \cdot \mathrm{kg}^{-1} \cdot \mathrm{min}^{-1}\right)$. Furthermore, the highest dose that was found to be selective to the pulmonary vasculature $\left(6 \mu \mathrm{g} \cdot \mathrm{kg}^{-1} \cdot \mathrm{min}^{-1}\right)$ was as potent as $40 \mathrm{ppm}$ of iNO (24). In contrast, i.v. or intratracheal administration of DEA/NO (half-life $\sim 2.1 \mathrm{~min}$ ) to lambs with pulmonary hypertension showed a nonselective vasodilation of the pulmonary and systemic circulations $(25,27)$. However, Brilli et al. $(18,19)$ demonstrated a selective pulmonary vasodilation in pigs with pulmonary hypertension after $\mathrm{EP} / \mathrm{NO}$ and DMAEP/NO were delivered by intratracheal instillation or nebulization. They postulated that this mode of delivery combined with the limited mucosal permeability of the tested NONOates (tertiary amine and cationic-charged end group) would permit selective pulmonary vasodilation $(18,19)$. These findings were reproduced by Jacobs et al. $(20,21)$ in a porcine model of acute lung injury using aerosolized DMAEP/NO with and without surfactant. To the best of our knowledge, the present study is the first to evaluate the effectiveness of the administration of a NONOate in GBS-induced pulmonary hypertension in newborn animals.

DPTA/NO is a tertiary amine with a cationic-charged end group. Its size and chemical structure molecule should minimize its transmucosal transit and systemic absorption after nebulization. Although the half-life of DPTA/NO ranges from 1 to $5 \mathrm{~h}$, the half-life of this agent is $3 \mathrm{~h}$ at $\mathrm{pH} 7.4$ and temperature of $37^{\circ} \mathrm{C}$ $(14,15)$. In the present study, the duration of action of DPTA/NO was shorter than $3 \mathrm{~h}$, as the temperature of the piglets was $38^{\circ} \mathrm{C}$. Moreover, the factors that influence delivery of nebulized drugs to ventilated patients, such as particle size, humidification, and positioning of the nebulizer in the circuit, will not significantly affect the delivery of nebulized DPTA/NO to the lower airway, as the DPTA/NO particles that deposit in the upper airways and respiratory circuit will continuously release $\mathrm{NO}$ and this gas will diffuse to the lower airways (28).

In this study, DPTA/NO nebulization significantly attenuated GBS-induced pulmonary hypertension for $120 \mathrm{~min}$. This 
Table 1. Changes in arterial blood gases and acid-base status during GBS infusion in PL and DPTA/NO groups

\begin{tabular}{|c|c|c|c|c|c|c|c|c|}
\hline \multirow[b]{2}{*}{ Time } & \multicolumn{4}{|c|}{$\mathrm{PL}(n=8)$} & \multicolumn{4}{|c|}{ DPTA/NO $(n=9)$} \\
\hline & $\mathrm{pH}$ & $\begin{array}{c}\mathrm{PaCO}_{2} \\
(\mathrm{~mm} \mathrm{Hg})\end{array}$ & $\begin{array}{c}\mathrm{PaO}_{2} \\
(\mathrm{~mm} \mathrm{Hg})\end{array}$ & $\begin{array}{c}\mathrm{BE} \\
(\mathrm{mmol} / \mathrm{L})\end{array}$ & $\mathrm{pH}$ & $\begin{array}{c}\mathrm{PaCO}_{2} \\
(\mathrm{~mm} \mathrm{Hg})\end{array}$ & $\begin{array}{c}\mathrm{PaO}_{2} \\
(\mathrm{~mm} \mathrm{Hg})\end{array}$ & $\begin{array}{c}\mathrm{BE} \\
(\mathrm{mmol} / \mathrm{L})\end{array}$ \\
\hline $15 \min$ & $7.44 \pm 0.04$ & $38 \pm 5$ & $382 \pm 134$ & $2.2 \pm 3.3$ & $7.42 \pm 0.02$ & $36 \pm 3$ & $380 \pm 47$ & $0.2 \pm 2.0$ \\
\hline $60 \mathrm{~min}$ & $7.44 \pm 0.07$ & $37 \pm 3$ & $347 \pm 133$ & $0.8 \pm 2.8$ & $7.43 \pm 0.04$ & $36 \pm 3$ & $326 \pm 62$ & $0.5 \pm 2.3$ \\
\hline $120 \mathrm{~min}$ & $7.39 \pm 0.06$ & $40 \pm 3$ & $330 \pm 136$ & $-0.4 \pm 3.2$ & $7.39 \pm 0.03$ & $39 \pm 3$ & $267 \pm 83$ & $-0.6 \pm 2.1$ \\
\hline
\end{tabular}

Values are expressed as mean \pm SD. There were no significant differences between groups.

$\mathrm{PaCO}_{2}$, arterial partial pressure of $\mathrm{CO}_{2} ; \mathrm{BE}$, base excess.

Table 2. Changes in pulmonary mechanics between PL and DPTA/NO groups during GBS infusion

\begin{tabular}{lccccc}
\hline & $* \mathrm{Crs}\left(\mathrm{mL} \cdot \mathrm{kg}^{-1} \cdot \mathrm{cm} \mathrm{H}_{2} \mathrm{O}\right)$ & & $* \mathrm{R}_{\mathrm{T}}\left(\mathrm{cm} \mathrm{H} \mathrm{H}_{2} \mathrm{O} \cdot \mathrm{L}^{-1} \cdot \mathrm{s}^{-1}\right)$ \\
\cline { 2 - 3 } \cline { 6 - 7 } Time & $\begin{array}{c}\mathrm{PL} \\
(n=10)\end{array}$ & $\begin{array}{c}\text { DPTA/NO } \\
(n=10)\end{array}$ & & $\begin{array}{c}\mathrm{PL} \\
(n=10)\end{array}$ & $\begin{array}{c}\text { DPTA/NO } \\
(n=10)\end{array}$ \\
\hline BL & $1.15 \pm 0.20$ & $1.18 \pm 0.26$ & & $33 \pm 5$ & $31 \pm 10$ \\
$15 \mathrm{~min}$ & $1.00 \pm 0.21$ & $1.02 \pm 0.21$ & & $37 \pm 4$ & $34 \pm 11$ \\
$60 \mathrm{~min}$ & $0.92 \pm 0.27$ & $1.00 \pm 0.26$ & & $37 \pm 7$ & $34 \pm 12$ \\
$120 \mathrm{~min}$ & $0.81 \pm 0.20$ & $0.95 \pm 0.24$ & & $42 \pm 8$ & $35 \pm 10$ \\
\hline
\end{tabular}

Values are expressed as mean $\pm \mathrm{SD}$.

* The decrease in respiratory compliance (Crs) and increase in total respiratory resistance (RT) during GBS infusion was significant in both groups over time, $p<0.01$. There was however no difference in pulmonary function between groups.

effect was accompanied by a significant decrease in Psa and SVR after DPTA/NO administration even though these values remained close to baseline. The vasodilatory effect was more pronounced in the pulmonary vasculature as illustrated by the significant decrease in PVR/SVR after DPTA/NO nebulization compared with PL. One possible explanation for the unexpected systemic effects is that the permeability of epithelial and endothelial junctions may be increased during GBS infusion, leading to "leakage" of the NONOate into the systemic circulation with subsequent $\mathrm{NO}$ release and vasodilation. In support of this possibility, Rojas et al. $(29,30)$ demonstrated morphologic and physiologic evidence of increased pulmonary vascular permeability during GBS toxin infusion in adult sheep and newborn lambs. In addition, selective pulmonary vasodilation of DPTA/NO was demonstrated in healthy newborn piglets with pulmonary hypertension induced by hypoxia and a thromboxane $\mathrm{A} 2$ agonist $(31,32)$.

Although a significant improvement in oxygenation has been demonstrated after nebulized NONOate was administered to young pigs with oleic acid-induced pulmonary hypertension (21), there was no difference in oxygenation between groups in the present study. This is consistent with the findings of Berger et al. (12), who demonstrated no significant improvement in gas exchange after iNO was administered to piglets with GBS-induced pulmonary hypertension. This may be explained by the presence of microvascular injury and protein leak into the perivascular space during GBS infusion, which may compromise gas exchange despite vasodilation of well-ventilated areas by iNO. In addition, although improvement in oxygenation observed after initiation of NO therapy in human infants results in part from a decrease in extrapulmonary shunting, it is very unlikely that this occurred in this model, as the ductus arteriosus of neonatal piglets has been shown to close functionally within $48 \mathrm{~h}$ of birth, and the pulmonary artery pressure never reached systemic levels during GBS infusion (33). Furthermore, the newborn piglets were ventilated with $100 \% \mathrm{O}_{2}$ and never became hypoxemic. Another possible explanation, however, for the lack of improvement in oxygenation in this study is that NO released from DPTA/NO may diffuse from well-ventilated lung regions to poorly ventilated areas with subsequent increase in blood flow to those regions, worsening the intrapulmonary shunt.

CO changes were not different between groups after DPTA/NO administration, and these findings are similar to those reported previously in NONOate-treated animals with pulmonary hypertension $(10,18,20,21,27)$. Because there was a significant decrease in Ppa and PVR, a significant improvement in CO should be expected. However, during GBS sepsis, several cytokines are released into the circulation and some of these agents may act directly as myocardial depressants $(5,34-36)$.

A significant metabolic acidosis was also observed during GBS infusion. Changes in the distribution of $\mathrm{CO}$, the "critical oxygen delivery" value, and a decreased oxygen delivery to some organs may be responsible for the metabolic acidosis observed during sepsis $(37,38)$. Consistent with other studies, the acid-base status did not differ significantly between groups in the present study $(12,27)$.

Although pulmonary vascular engorgement may affect pulmonary mechanics (4), there was no difference in pulmonary function between the groups in the present study. Similar results were previously reported in piglets that were treated with the NONOate DMAEP/NO during pulmonary hypertension induced by oleic acid (21). It should be noted, however, that although there was a statistically significant increase in total respiratory resistance and decrease in respiratory compliance during GBS infusion, as previously reported in the literature $(4,39)$, the changes in the present study were minimal.

Sudden withdrawal of iNO has been associated with the rebound phenomenon, and an increased level of endothelin is believed to be one of the principal contributors to this phenomenon (40), yet some investigators believe that a combination of factors, such as diminished endogenous NO production combined with increased, unopposed action of vasoconstrictors, may be responsible for this phenomenon (41-43). Therefore, we speculate that because DPTA/NO will continuously release NO over a period of three to four half-lives (3-4 h), this would allow enough time for vasoconstricting and vasodilating factors to equilibrate $(19,32)$. 


\section{CONCLUSION}

In summary, the present study demonstrated the effectiveness of a nebulized NONOate, DPTA/NO, in attenuating GBSinduced pulmonary hypertension in newborn piglets. In addition, the vasodilatory effect of DPTA/NO was more pronounced in the pulmonary than in the systemic vasculature. We speculate that DPTA/NO may have clinical application in the management of pulmonary hypertension secondary to sepsis in the newborn infant. Furthermore, the delivery of NO in the form of a NONOate could potentially offer a significant clinical advantage by simplifying delivery and offering intermittent instead of continuous therapy, especially during transport of a sick neonate.

\section{REFERENCES}

1. Meadow WL, Meus PJ 1986 Early and late hemodynamic consequences of group B beta streptococcal sepsis in piglets: effects on systemic, pulmonary, and mesenteric circulations. Circ Shock 19:347-356

2. Berger JI, Gibson RL, Clarke WR, Standaert TA, Redding GJ, Henderson WR Jr, Truog WE 1993 Effect of amrinone during group B Streptococcus-induced pulmonary hypertension in piglets. Pediatr Pulmonol 16:303-310

3. Truog WE, Gibson RL Jr, Henderson WR Jr, Redding GJ, Standaert TA 1992 Effect of pentoxifylline on cytokine- and eicosanoid-induced acute pulmonary hypertension in piglets. Pediatr Res 31:163-169

4. Suguihara C, Goldberg RN, Hehre D, Bancalari A, Bancalari E 1987 Effect of cyclooxygenase and lipoxygenase products on pulmonary function in group B streptococcal sepsis. Pediatr Res 22:478-482

5. Runkle B, Goldberg RN, Streitfeld MM, Clark MR, Buron E, Setzer ES, Bancalari E 1984 Cardiovascular changes in group B streptococcal sepsis in the piglet: response to indomethacin and relationship to prostacyclin and thromboxane A2. Pediatr Res 18:874-878

6. Meadow WL, Meus PJ 1984 Hemodynamic consequences of tolazoline in neonatal group B streptococcal bacteremia: an animal model. Pediatr Res 18:960-965

7. Hammerman C, Aramburo MJ, Choi JH 1989 Prostaglandin E1 selectively reduces group B beta-hemolytic streptococci-induced pulmonary hypertension in newborn piglets. Am J Dis Child 143:343-347

8. Goldman AP, Tasker RC, Haworth SG, Sigston PE, Macrae DJ 1996 Four patterns of response to inhaled nitric oxide for persistent pulmonary hypertension of the newborn. Pediatrics 98:706-713

9. Roberts JD Jr, Fineman JR, Morin FC 3rd, Shaul PW, Rimar S, Schreiber MD, Polin RA, Zwass MS, Zayek MM, Gross I, Heymann MA, Zapol WM 1997 Inhaled nitric oxide and persistent pulmonary hypertension of the newborn. The Inhaled Nitric Oxide Study Group. N Engl J Med 336:605-610

10. Nelin LD, Moshin J, Thomas CJ, Sasidharan P, Dawson CA 1994 The effect of inhaled nitric oxide on the pulmonary circulation of the neonatal pig. Pediatr Res 35:20-24

11. Roberts JD Jr, Chen TY, Kawai N, Wain J, Dupuy P, Shimouchi A, Bloch K, Polaner D, Zapol WM 1993 Inhaled nitric oxide reverses pulmonary vasoconstriction in the hypoxic and acidotic newborn lamb. Circ Res 72:246-254

12. Berger JI, Gibson RL, Redding GJ, Standaert TA, Clarke WR, Truog WE 1993 Effect of inhaled nitric oxide during group B streptococcal sepsis in piglets. Am Rev Respir Dis 147:1080-1086

13. Lavoie A, Hall JB, Olson DM, Wylam ME 1996 Life-threatening effects of discontinuing inhaled nitric oxide in severe respiratory failure. Am J Respir Crit Care Med 153:1985-1987

14. Hrabie JA, Arnold EV, Citro ML, George C, Keefer LK 2000 Reaction of nitric oxide at the beta-carbon of enamines. A new method of preparing compounds containing the diazeniumdiolate functional group. J Org Chem 65:5745-5751

15. Keefer LK, Nims RW, Davies KM, Wink DA 1996 "NONOates" (1-substituted diazen-1-ium-1,2-diolates) as nitric oxide donors: convenient nitric oxide dosage forms. Methods Enzymol 268:281-293

16. Fitzhugh AL, Keefer LK 2000 Diazeniumdiolates: pro- and antioxidant applications of the "NONOates." Free Radic Biol Med 28:1463-1469

17. Morley D, Keefer LK 1993 Nitric oxide/nucleophile complexes: a unique class of nitric oxide-based vasodilators. J Cardiovasc Pharmacol 22:S3-S9
18. Brilli RJ, Krafte-Jacobs B, Smith DJ, Roselle D, Passerini D, Vromen A, Moore L, Szabo C, Salzman AL 1997 Intratracheal instillation of a novel NO/nucleophile adduct selectively reduces pulmonary hypertension. J Appl Physiol 83:1968-1975

19. Brilli RJ, Krafte-Jacobs B, Smith DJ, Passerini D, Moore L, Ballard ET 1998 Aerosolization of novel nitric oxide donors selectively reduce pulmonary hypertension. Crit Care Med 26:1390-1396

20. Jacobs BR, Smith DJ, Zingarelli B, Passerini DJ, Ballard ET, Brilli RJ 2000 Soluble nitric oxide donor and surfactant improve oxygenation and pulmonary hypertension in porcine lung injury. Nitric Oxide 4:412-422

21. Jacobs BR, Brilli RJ, Ballard ET, Passerini DJ, Smith DJ 1998 Aerosolized soluble nitric oxide donor improves oxygenation and pulmonary hypertension in acute lung injury. Am J Respir Crit Care Med 158:1536-1542

22. Hampl V, Tristani-Firouzi M, Hutsell TC, Archer SL 1996 Nebulized nitric oxide/ nucleophile adduct reduces chronic pulmonary hypertension. Cardiovasc Res 31:55-62

23. Cornfield DN, Martin EB, Hampl V, Archer SL 1999 Aerosol delivery of diethylenetriamine/nitric oxide, a nitric oxide adduct, causes selective pulmonary vasodilation in perinatal lambs. J Lab Clin Med 134:419-425

24. Adrie C, Hirani WM, Holzmann A, Keefer L, Zapol WM, Hurford WE 1998 Selective pulmonary vasodilation by intravenous infusion of an ultrashort half-life nucleophile/nitric oxide adduct. Anesthesiology 88:190-195

25. Adrie C, Ichinose F, Holzmann A, Keefer L, Hurford WE, Zapol WM 1998 Pulmonary vasodilation by nitric oxide gas and prodrug aerosols in acute pulmonary hypertension. J Appl Physiol 84:435-441

26. Welch E, Duara S, Suguihara C, Bandstra E, Bancalari E 1994 Validation of cardiac output measurements with noninvasive Doppler echocardiography by thermodilution and Fick methods in newborn piglets. Biol Neonate 66:137-145

27. Vanderford PA, Wong J, Chang R, Keefer LK, Soifer SJ, Fineman JR 1994 Diethylamine/nitric oxide (NO) adduct, an NO donor, produces potent pulmonary and systemic vasodilation in intact newborn lambs. J Cardiovasc Pharmacol 23:113-119

28. Dhand R, Tobin MJ 1997 Inhaled bronchodilator therapy in mechanically ventilated patients. Am J Respir Crit Care Med 156:3-10

29. Rojas J, Larsson LE, Hellerqvist CG, Brigham KL, Gray ME, Stahlman MT 1983 Pulmonary hemodynamic and ultrastructural changes associated with Group B streptococcal toxemia in adult sheep and newborn lambs. Pediatr Res 17:1002-1008

30. Rojas J, Green RS, Hellerqvist CG, Olegard R, Brigham KL, Stahlman MT 1981 Studies on group B beta-hemolytic Streptococcus. II. Effects on pulmonary hemodynamics and vascular permeability in unanesthetized sheep. Pediatr Res 15:899-904

31. Young KC, Ladino J, Navarrete C, Dabrowska K, Hehre D, Bancalari E, Suguihara C 2004 The effect of a nebulized NO donor, DPTA/NO, on acute hypoxic pulmonary hypertension in newborn piglets. Biol Neonate 85:195-202

32. Lam CF, van Heerden PV, Ilett KF, Caterina P, Filion P 2003 Two aerosolized nitric oxide adducts as selective pulmonary vasodilators for acute pulmonary hypertension. Chest 123:869-874

33. Rowe RD, Sinclair JD, Kerr AR, Gage PW 1964 Duct flow and mitral regurgitation during changes of oxygenation in newborn swine. J Appl Physiol 19:1157-1163

34. Del Moral T, Goldberg RN, Urbon J, Suguihara C, Martinez O, Stein-Streilein J, Feuer WJ, Bancalari E 1996 Effects of treatment with pentoxifylline on the cardiovascular manifestations of group B streptococcal sepsis in the piglet. Pediatr Res 40:469-474

35. Goldberg RN, Suguihara C, Martinez O, Bancalari A, Clark MR, Bancalari E 1988 The role of leukotrienes in the late hemodynamic manifestations of group B streptococcal sepsis in piglets. Prostaglandins Leukot Essent Fatty Acids 33:191-198

36. Goldberg RN, Suguihara C, Streitfeld MM, Bancalari A, Clark MR, Bancalari E 1986 Effects of a leukotriene antagonist on the early hemodynamic manifestations of group B streptococcal sepsis in piglets. Pediatr Res 20:1004-1008

37. Meadow WL, Rudinsky BF, Strates E, Komar KJ 1987 Oxygen delivery, oxygen consumption, and metabolic acidosis during group B streptococcal sepsis in piglets. Pediatr Res 22:509-512

38. Barefield ES, Oh W, Stonestreet BS 1992 Group B Streptococcus-induced acidosis in newborn swine: regional oxygen transport and lactate flux. J Appl Physiol 72:272277

39. Sandberg K, Engelhardt B, Hellerqvist C, Sundell H 1987 Pulmonary response to group B streptococcal toxin in young lambs. J Appl Physiol 63:2024-2030

40. Wedgwood S, McMullan DM, Bekker JM, Fineman JR, Black SM 2001 Role for endothelin-1-induced superoxide and peroxynitrite production in rebound pulmonary hypertension associated with inhaled nitric oxide therapy. Circ Res 89:357-364

41. Ivy DD, Kinsella JP, Ziegler JW, Abman SH 1998 Dipyridamole attenuates rebound pulmonary hypertension after inhaled nitric oxide withdrawal in postoperative congenital heart disease. J Thorac Cardiovasc Surg 115:875-882

42. Black SM, Heidersbach RS, McMullan DM, Bekker JM, Johengen MJ, Fineman JR 1999 Inhaled nitric oxide inhibits NOS activity in lambs: potential mechanism for rebound pulmonary hypertension. Am J Physiol 277:H1849-H1856

43. Atz AM, Adatia I, Wessel DL 1996 Rebound pulmonary hypertension after inhalation of nitric oxide. Ann Thorac Surg 62:1759-1764 